\title{
Mind-Body Skills Elective: A 7-year Follow-up of Health Professions Students
} \author{
Breuner $\mathrm{CC}^{10}$ and Erlanger $\mathrm{L}^{11}$ \\ ${ }^{1}$ Department of Biomedical Informatics and Medical Education, University of Washington, USA \\ ${ }^{2}$ Department of Pharmacology, University of Washington, USA \\ ${ }^{3}$ Department of Biomedical Informatics and Medical Education, University of Washington, USA \\ ${ }^{4}$ Licensed Mental Health Counselor, Olive Tree Healing Arts, USA
}

Scott $\mathrm{CS}^{1}$, Vincenzi $\mathrm{FF}^{2}$, Smith $\mathrm{DS}^{3}$, Gorrin $\mathrm{K}^{4}$, Trantham $\mathrm{JG}^{5}$, Byrne $\mathrm{RA}^{6}$, Loshi $\mathrm{LAM}^{7}$, Adams $\mathrm{CA}^{8}$, Dawson $\mathrm{KN}^{9}$,

${ }^{5}$ Department of Psychiatry and Behavioral Medicine, University of Washington, USA

${ }^{6}$ Department of Family Medicine, Tulane University, USA

${ }^{7}$ Licensed Clinical Psychologist, Wise Mind Institute, USA

${ }^{8}$ Department of Family Medicine, University of Washington, Washington

${ }^{9}$ Department of Pharmacy, University of Washington, USA

${ }^{10}$ Department of Pediatrics and Adolescent Medicine, University of Washington, USA.

${ }^{11}$ Department of Family Medicine, University of Washington, USA

Submission: December 04, 2018; Published: February 06, 2019

*Corresponding author: Scott CS, Department of Biomedical Informatics and Medical Education, University of Washington, 1959 Pacific Street NE, Box 357240, Seattle, Washington, USA.

\section{Abstract}

Purpose: Student and clinician burnout in the health professions have been reported across the education spectrum. Burnout has been linked to medical errors and decreases in performance. Increasingly over the past two decades, health professional schools are implementing mindfulness-based stress reduction courses. Since 2010, the University of Washington has offered an inter-professional mind-body skills course to graduate students in the health professions. This study examines the longer-term impacts of experiential mind-body skills training on graduate health professional students. The objectives of this 7-year follow-up study, the first of its kind, were:

1. To determine the value that medical, nursing and pharmacy students retrospectively attribute to an eight-week mind-body medicine course, for personal and professional development and for ameliorating chronic stress

2. To determine the extent to which former students would recommend a similar instructional experience for their peers.

Method: An online follow-up survey was disseminated in late 2016 to early 2017 to 319 potential respondents who had taken the course between 2010 and 2017. We filtered the results into subsets based on the type of student.

Results: Results suggest that most students retrospectively ascribed beneficial effects to having been exposed to a variety of meditation techniques, particularly mindfulness and meditation practices.

Conclusion: Most former students ascribed beneficial effects to learning mind-body skills during graduate school. We conclude that such offerings may contribute to the development of more resilient health professionals. We suggest offering similar elective mind-body skills courses to students in the health professions programs (246 words).

Keywords: Mind body skills; Stress mitigation; Resilience; Chronic stress

\section{Introduction}

Student and clinician burnout have been reported across the medical education spectrum [1,2]. Disconcertingly high rates of student burnout, defined as constellations of symptoms associated with a professional practice that can result in emotional and personal exhaustion and/or disillusionment, have been reported [3-5]. Within medical, nursing and pharmacy school environments a myriad of stressors exist that can result in acute and chronic stress that in turn can lead to personal burnout [6-13]. Clinician burnout has been associated with increases in clinician medical errors [14-15] and overall decreases in performance [16]. Authors from the fields of medicine, dentistry, 
nursing, and social work have called for multiple approaches to address the problem of burnout $[12,18]$. Although burnout was documented among practicing pharmacists many years ago [2] little appears to have been done to alleviate the stresses of pharmacy education or practice.

With increasing frequencies over the past two decades medical and professional schools have started offering mindfulness-based stress management and stress reduction offerings [19-23]. Studies examining the efficacy of mindfulnessbased stress reduction programs suggest that they can lower levels of psychological distress in medical students [19,24,25]. An elective mind-body skills (MBM) course was first offered at the University of Washington (U_) in the 2004-05 academic year. This was an attempt to ameliorate at least some of the stressors that are known to interfere with learning in professional school environments. The course was designed to help students from the health sciences manage anxiety and stress. Initially, students were second-year medical students and graduate nursing students. Later the course was opened to pharmacy students and, on a space-available basis, to a few students from other professional schools such as public health and education. The objective of this study was to determine the extent to which former medical, pharmacy and nursing students retrospectively viewed the course's MBM content and experiences as having been valuable for their personal and professional development, and for coping with chronic stress. It was also designed to determine whether the former MBM students would recommend similar instructional experiences for others within their profession. The U_course, Introduction to Mind Body Medicine - An Experiential Elective, was adapted from a mind body skills program offered by the Center for Mind-Body Medicine and was similar to a course at Georgetown University Medical School [22]. Initially, the U_ MBM course was offered exclusively to medical and graduate nursing students. Later, we included pharmacy students. As a 'conjoint' course, the founding faculty members were from more than one professional school. As the course evolved, volunteer faculty also came from a variety of healthcare professional practices.

The UW mind-body medicine (MBM) course focused on activities that included various 'mindfulness practices (mindful meditation, mindful eating, walking meditation), various other meditation practices (quiet meditations, shaking meditations, guided imagery, yoga), as well as discussions about nutrition, mirror neurons, and spirituality. It was apparent from the outset that certain activities 'resonated' with some students, but not with others, and vice-versa. Since 2010, depending on faculty availability, from 2 to 4 concurrent sections of the U_'s multidisciplinary MBM course were offered during both the autumn and winter quarters. Each small group consisted of between 8 and 12 students. Each section of the course met for eight weeks for 3-hour sessions, with one or two faculty 'guides,' most of who were volunteers. Typically, sessions opened with a brief meditation, a 'check-in' and then an activity that provided an experience aimed at exploring mind-body connections. Listening respectfully without interruptions was the rule. Students were reminded that they were there to experiences mind-body practices and to engage in self-exploration, not to fix others. Modeling the confidentiality of the healer/patient relationship, we emphasized that anything that transpired during the sessions was to be held in complete confidence.

Each week's session focused on students engaging in, one or more MBM experiences. Each weekly session began with a brief mindfulness meditation. This meditation was followed by each participant "checking-in" with a summary of how the previous week had gone for them. These brief check-ins provided the group with individual student's and guide's overviews of their successes or challenges during the previous week at incorporating mindfulness and other mind-body practices, including exercise, into their daily routines. The check-in allowed students and the faculty guides to think about and share with their course colleagues their experiences and related feelings in a nonjudgmental, supportive environment. The faculty facilitator/ guides participated fully in the group process and presumably modeled these behaviors, sharing their challenges in keeping up with the "mindfulness" homework activities. After the checkin period, the week's focal point subject was briefly presented, sometimes with a brief PowerPoint presentation followed by group discussion and Q\&A. The remainder of the sessions, usually 70 to $75 \%$ of the time, was devoted to experiential practice with a variety of meditation techniques and guided imagery. We also provided a closing meditation at the end of each session.

As a prelude to preparing genograms, students were encouraged to contact significant family members (such as parents, aunts, uncles, and grandparents). The goal was to seek information about family members' views of family strengths, beliefs, values, stressors, diseases and relationships about which the students might not have been aware. A genogram is a family tree that highlights one's family's strengths, beliefs, and values, stressors, diseases, as well as the extent to which relationships were close, distant, cut-off and/or conflicted. A review of genograms is available online [26]. During the last three sessions, a portion of in-class time was provided for each student to prepare and then share his or her family's three-generation genogram. Over 95 percent of participants chose to present their genogram and share any insights they might have gained regarding the extent to which their family's methods of coping with and managing stress. Insights about how their experiences in their families shaped their ability to cope with chronic stress were shared with the group.

An earlier pre- and post-course effectiveness study of the UW MBM course indicated that the course was needed and effective and that it had lasting short-term impacts. The intervention and comparison groups, which differed significantly with respect to anxiety levels at the beginning of the mind-body course (time 1), were indistinguishable from each other 10 weeks later at the end of the course (time 2). Three months after the course concluded 
(time 3), the observed lowered anxiety levels in the intervention group were sustained [19].

\section{Method}

\section{The subjects}

Medical, nursing, and pharmacy students had priority for registering for the course. Students from other professional schools were allowed to register on a space-available basis. We excluded students from other schools from the analyses. After identifying the pool of health professional students who had completed the course during the 7-year timeframe between 2010 and 2017, we embarked on the process of locating valid emails. We finalized a list of 319 "likely valid" emails.

\section{The survey}

We designed an online follow-up survey to help ascertain former MBM students' insights into the effectiveness of the course for mitigating the effects of chronic stress. The survey assured potential respondents of confidentiality and was approved by the U_ Human Subjects Committee. Four related items queried about attribution of course impacts. These were

1. Would you attribute significant positive long-term impact(s) on you personally as a result of your having elected to take our MBM Course?

2. Would you attribute significant positive long-term impact(s) on the way you professionally practice as a result of your having elected to take our MBM Course?

3. Would you recommend a similar experiential course of instruction for friends and family?

4. Would you recommend a similar experiential course of instruction for your professional colleagues? The four mutually exclusive, categorical response options were:

a) Absolutely yes

b) Yes, but I expected more

c) Had a slight impact

d) Absolutely not.

The survey also included eight items that asked about the extent to which the course's eight MBM components/concepts helped mitigate the effects of stress.

The eight course components/concepts were: Mindfulness, Meditation practices, Shaking meditation, Guided imagery, Mirror neurons, Yoga, Spirituality, and Genograms. The four mutually exclusive, categorical options were
a) Yes, very effective
b) Yes, moderately
c) Only slightly
d) No, didn't resonate with me

For each of the eight course components/concepts, the survey also asked about "the extent to which you have incorporated course components/concepts into your personal practices." The four mutually exclusive, categorical response options were
a) Yes, very effective
b) Yes, moderately
c) Only slightly
d) No, didn't resonate with me

Finally, we provided a response box for respondents "to offer an entirely optional reflection about the course.

The survey was disseminated in late 2016 and early 2017 via the UW's Online Catalyst System to 319 medical, nursing and pharmacy students who had taken the course during the period between 2010-2017 and for whom we were able to identify likely still current contact information. Three automated reminders were sent to non-responders.

\section{Results}

\section{Response rates}

The unadjusted response rate was 54\% (172/319). We determined that 125 of the 319 distributed survey invitations (39\%) remained either unopened or were returned as undeliverable. For that reason, we decided to adjust the response rate accordingly. This yielded a total of 194 surveys that had been viewed by the former medical, nursing and pharmacy students. Of the 194, 22 survey recipients viewed but did not complete the survey. This resulted in an overall response rate of $87 \%(172 / 194)$. Adjusted response rates for students who took the course between 4 and 7 years ago (2010-13) were: medical students $93 \%$ (53 of 57), nursing students $88 \%$ (7 of 8), pharmacy students $91 \%$ (10 of 11) and other professional school students $92 \%$ (12 of 13). Adjusted response rates for students who took the course more recently (2014-17) were: medical students $84 \%$ (36 of 43), nursing students $92 \%$ (12 of 13 ), pharmacy students $85 \%$ (17 of 20) and other professional school students $86 \%$ (25 of 29).

\section{Usefulness of MBM modalities for mitigating stress}

The course provided eight categories of mind/body experiential activities. These are shown in Table 1 in decreasing order based on the percent indicating that the category was "very" effective for mitigating stress. Overall, the most effective activities for mitigating stress were mindfulness, meditation practices, and yoga. These were viewed as at least "moderately" effective by at least $75 \%$ of respondents. Guided imagery and spirituality were viewed as somewhat less effective but were cited as at least "moderately" effective for mitigating stress by a majority of respondents. Genograms, information about mirror neurons, and shaking meditation resonated only slightly or not at all for the majority of respondents. 
Journal of Complementary Medicine \& Alternative Healthcare

Table 1: Usefulness of the MBM Modality for Mitigating Stress.

\begin{tabular}{|c|c|c|c|c|}
\hline & Very Effective & Moderately & Slightly & Didn't resonate \\
\hline Mindfulness ( $\mathrm{n}=135)$ & $60 \%$ & $31 \%$ & $6 \%$ & $3 \%$ \\
\hline Meditation Practices ( $=135)$ & $47 \%$ & $36 \%$ & $14 \%$ & $3 \%$ \\
\hline Yoga (n = 135) & $40 \%$ & $35 \%$ & $16 \%$ & $10 \%$ \\
\hline Guided Imagery ( $=135)$ & $28 \%$ & $34 \%$ & $26 \%$ & $13 \%$ \\
\hline Spirituality ( $=135)$ & $27 \%$ & $33 \%$ & $24 \%$ & $15 \%$ \\
\hline Genograms ( $=135)$ & $16 \%$ & $33 \%$ & $29 \%$ & $26 \%$ \\
\hline Mirror Neurons (n=135) & $11 \%$ & $27 \%$ & $26 \%$ & $33 \%$ \\
\hline Shaking $(\mathrm{n}=135)$ & $9 \%$ & $17 \%$ & & $48 \%$ \\
\hline
\end{tabular}

As shown in Table 1, over $75 \%$ of responding medical, nursing and pharmacy students indicated that meditation and mindfulness practices were "very" or "moderately" effective for mitigating stress. Yoga, guided imagery, and spirituality for stress mitigation were viewed as "very" or "moderately" effective by just over $60 \%$ of responding medical, nursing and pharmacy students. Discussions of the importance of family history, experiences and values in understanding stress origins, as reflected in student-generated and shared genograms, was viewed as "very" or "moderately" effective by $40 \%$ of responding medical, nursing and pharmacy students. The role of "mirror neurons" in listening to, for understanding the feelings of others (empathy), and for communicating feelings was cited as "very" or "moderately" effective by approximately $25 \%$ of responding medical and pharmacy students but by over $60 \%$ of the nursing students. We introduced the concept of mirror neurons by viewing a NOVA Science Now program that originally aired on 25 Jan 2005. Discussion of mirror neuron implications to mindbody considerations followed. The NOVA Mirror Neuron Video is no longer available for streaming from PBS but it is available on YouTube.

Shaking meditation, promoted by OSHO as kundalini meditation, involves a series of body movements including shaking, dancing, and quiet meditation guided by music. It is a technique that may challenge the 'comfort zone' of many individuals and did not resonate with half of the respondents. The music is available on CD or online. [27] A number of websites now promote and present discussions and video demonstrations of shaking meditation [28,29].

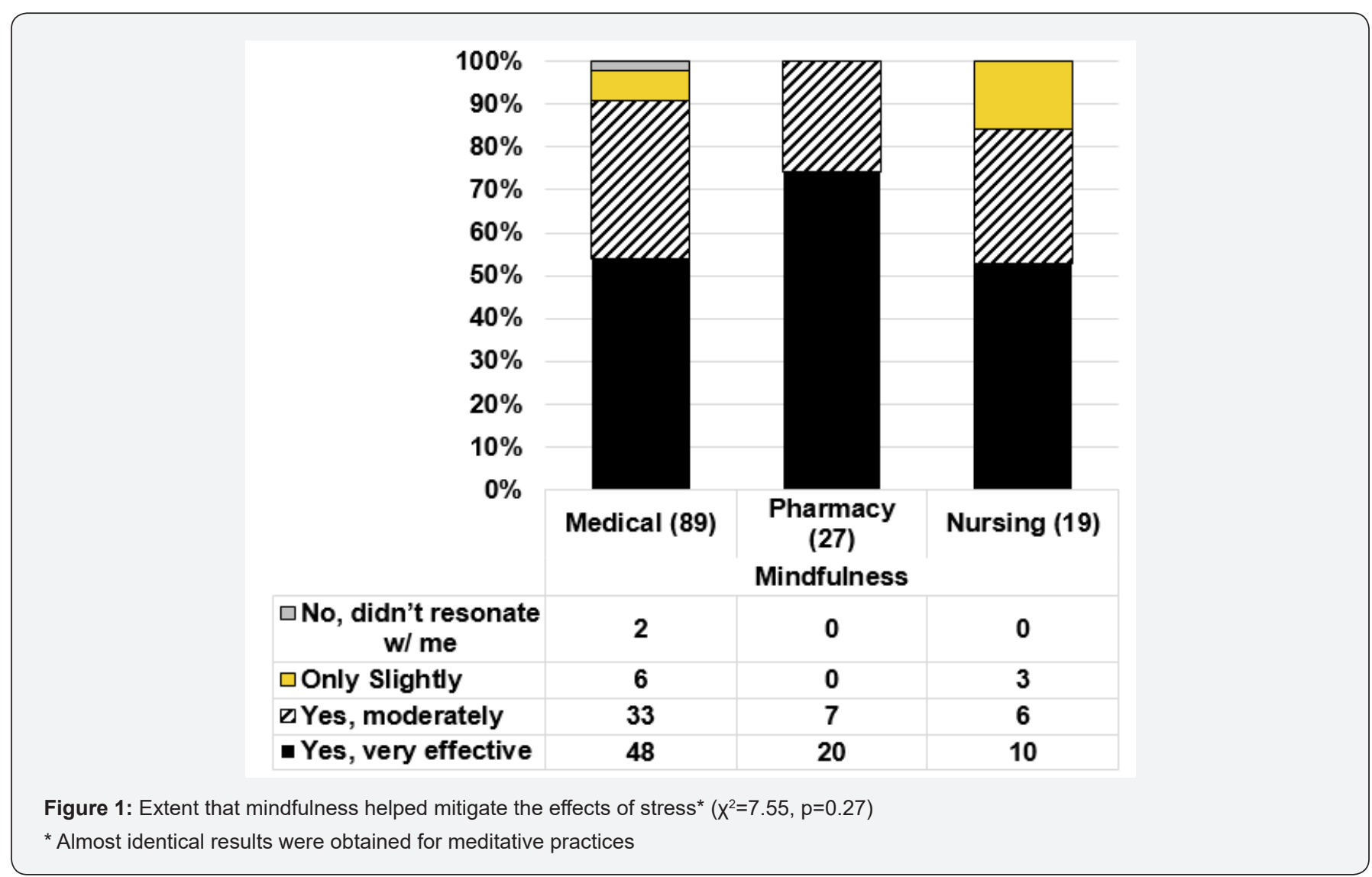


Figure 1 presents the extent to which former medical, nursing, and pharmacy students reported that the top-rated "mindfulness" practices helped students mitigate the effects of stress. The majority of all three types of clinicians indicated that the course had been "very effective" in helping them mitigate the effects of their stress (pharmacy students 74\%, medical students $54 \%$, and nursing students 53\%). Ninety-eight percent (98\%) of medical and $100 \%$ of pharmacy respondents indicated that the course was "very" or "moderately" effective for mitigating the effects of stress. Eighty-four (84\%) of nursing students indicated that "mindfulness" practices were "very" or "moderately" effective for mitigating the effects of stress. Two medical student respondents $(2 \%)$ indicated that mindfulness did not resonate with them.

Very similar results were obtained for "mediation practices". The vast majority of former medical, nursing, and pharmacy students reported that "meditation practices" helped them mitigate the effects of stress. The majority of former medical, pharmacy, and nursing students indicated that the course's meditation experiences were "very effective" in helping them mitigate the effects of their stress. All former pharmacy students indicated that the course's meditation experiences had been either "very" or "moderately" effective at helping mitigate the effects of stress. Similar percentages for medical and nursing students were $91 \%$ and $84 \%$, respectively. Four percent of former medical students $(4 \%)$ indicated that the course's meditation practices did not resonate with them.

\section{Long-term professional \& personal impacts}

Figures 2 presents the extent to which former medical, pharmacy and nursing students attributed long-term course impacts on their professional practice. When asked whether as a result of having elected to take this course they would attribute significant positive long-term impacts on the way they professionally practice, all former medical, pharmacy and nursing students responded that the course had at least a "slight impact" on their professional practice. The percentages of former medical, pharmacy and nursing students indicating "Absolutely yes" that they would attribute significant positive long-term impacts on their professional practice, were 46, 59, and $32 \%$, respectively.

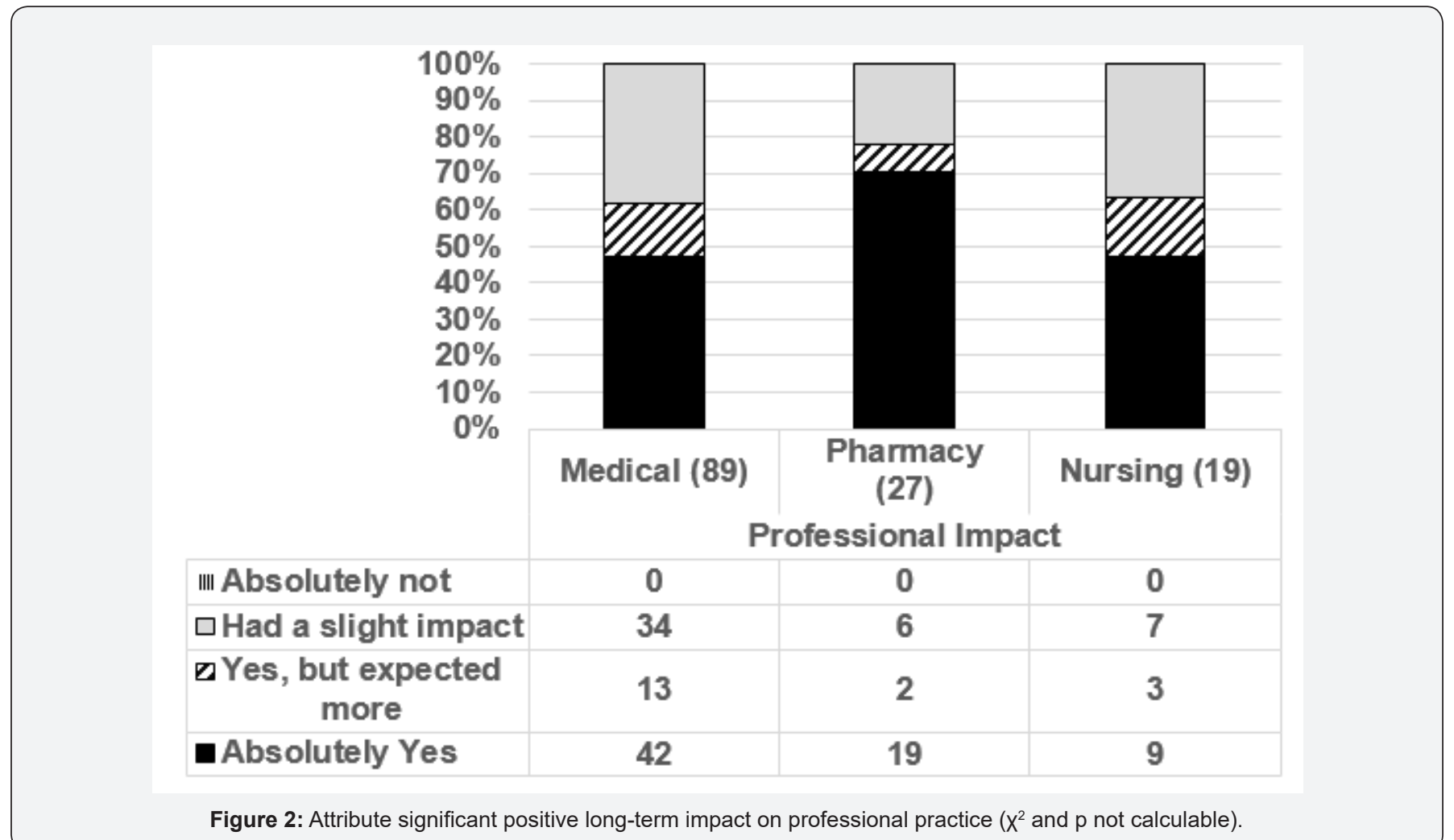

Figure 3 presents the extent to which former medical, pharmacy and nursing students attributed long-term course impacts on them. Two medical students $(2 \%)$ indicated that the course's meditation practices did not resonate with them. The percentages of former medical, pharmacy and nursing students that indicated "Absolutely yes" that they would attribute significant positive long-term impacts to the course's meditation practices were $40,44 \%$, and $47 \%$, respectively. The percentages of former medical, pharmacy and nursing students that indicated "Absolutely yes" that they would attribute significant positive long-term impacts or "Yes, but I expected more" were 54, 59, and $63 \%$, respectively. Respondents from medicine, nursing and pharmacy highly recommended a similar experiential course of instruction for their professional colleagues. Over $70 \%$ of the former medical, pharmacy and nursing students responded "Absolutely Yes" they would recommend a similar experiential 
course to their colleagues for professional colleagues (medical $72 \%$, pharmacy $85 \%$, and nursing $86 \%$ ).

\section{Discussion}

Overall, the majority of former health profession students who participated in the course reported positive long-term impacts. The most effective of the MBM activities for mitigating stress were mindfulness, meditation practices, and yoga. Mindfulness was also the approach that was most commonly incorporated into personal practices. The majority of respondents also reported that guided imagery and spirituality were viewed as helpful and at least "moderately" effective for mitigating stress. Genograms and information about mirror neurons resonated with less than half of respondents. By sharp contrast, the shaking meditation was the least likely to be incorporated into personal practices; it and was viewed as being "very" or "moderately" effective by fewer than $30 \%$ of respondents. Shaking may have been outside the comfort zone of some students.

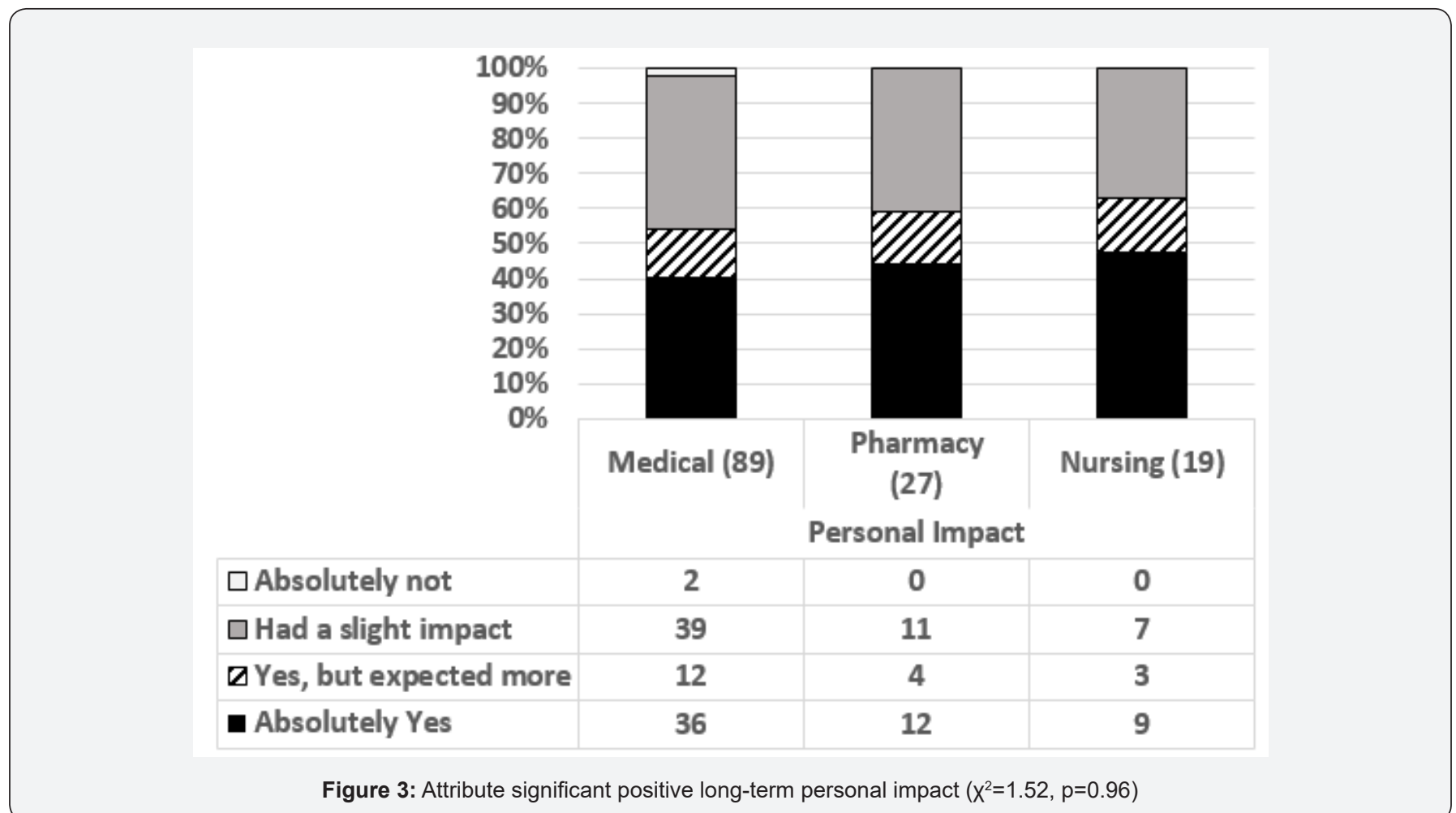

For the majority of former UW medical, nursing, and pharmacy students, experiences related to the top-rated practice category of mindfulness indicated that the course had been "very effective" in helping them mitigate the effects of stress. The vast majority of respondents viewed mindfulness practices as "very" or "moderately" effective for mitigating the effects of stress. That said, two medical students (2\%) indicated that the course did not resonate with them at all concerning the mitigating the effects of mindfulness. All pharmacy or nursing students indicated that mindfulness practices were at least "slightly" effective for mitigating the effects of stress. The overwhelmingly positive perceptions of the effectiveness of mindfulness practices provide strong support for offering mindfulness experiences to students in these health professions, at least as a part of elective offerings. It should be said that in this study we examined perceptions of effectiveness, not objective measures of the effectiveness of mindfulness. A cautionary note; some psychologists, neuroscientists and meditation experts contend that hype about mindfulness may be outpacing science [30].

All former pharmacy students and over three-quarters of former medical and nursing students reported that the course's meditation experiences were at least "very" or "moderately" helpful for reducing the effects of stress. Again, former medical students were slightly less enthusiastic but still overwhelmingly positive about the utility of meditation experiences for helping them mitigate the effects of stress. All respondents attributed some long-term course impacts on their professional practices. Likewise, the vast majority of respondents attributed long-term personal impacts to the course, although $2 \%$ of medical students indicated that they did not attribute any significant personal impacts to the course. Most importantly, the vast majority of these former MBM students from the three health professions indicated "absolutely yes" they would recommend such a course for their colleagues.

This study provides evidence that mind-body techniques, particularly mindfulness, when offered in an elective, interprofessional, small group setting, are viewed positively over time and may help reduce the high levels of stress encountered within the healthcare professions. These results suggest that skillsbased mindfulness courses for health professions students may serve to reduce burnout in future clinicians. At the University of Washington we are fortunate to have several health professional 
schools on the same campus. Some of our nursing students had many years of clinical experience whereas most medical and pharmacy students were relatively early in their training. The result was inter-professional and inter-generational communication between diverse students from different schools. From the authors' point of view, this was an important part of the small group experience. Insights into the personal viewpoints of students of other professions, as gained in small group settings, may help lay the foundation for more mutually empathic 'team' approaches to healthcare in the future, but that remains to be seen. There have been efforts in various institutions to train students together for technical details of clinical practice, but evidence-based results regarding health care processes and patient outcomes have not been definitive [31].

The majority of our former UW students absolutely recommend that such experiential MBM courses be offered to help students cope with chronic stress. We hypothesize that our findings should generalize to other health professions such as physician's assistant, dental, physical therapy, rehabilitation education and the like. Our results support the contention that experiential mind-body, stress management courses would contribute to the development of more resilient health professionals as they enter and pursue their professional practice years.

\section{Limitations}

Respondents had completed the course anywhere from 7 years ago to 6 months prior. Thus, it is possible that with the passage of time some of the reported longer-term impacts might have been slightly lower had all students taken the course 7 years prior to the study. There is likely some attrition bias given the number of students who were found to have non-working emails. This may have resulted in an over-representation of students who took the course more recently.

\section{Implications}

Health professional education and practice is well known to be challenging and highly stressful. This study suggests that providing mind-body medicine experiences during the formative educational years of health professionals is likely to enhance their ability to cope with personal and professional stress. Therefore, we recommend that health professional schools offer elective, experiential MBM courses. We also recommend formal training of faculty members to be "champions" of such courses and provision of dedicated quiet space, stationery supplies, music, multiple yoga mats, etc.

\section{Recommendation for Future Studies}

Multi-institutional follow-up studies that compare and contrast results from similar courses at different locales, and perhaps at different points in time, would certainly expand upon our findings. It would be beneficial to follow-up students who have completed similar experiential MBM courses over longer periods of time. These would more precisely quantify how the impressions and effects are impacted by passage of time and years of clinical practice. Future study designs should consider incorporating validated burnout, stress, and anxiety assessments to quantitatively measure the effects of such courses over longer periods of time and inclusion within the study designs of comparison/control groups [23]. It would be useful as well to evaluate with mixed method assessments the subjective preferences of the students for the different mindbody practices taught. This would help clarify those practices from which students would be most likely to benefit. Finally, it could be useful to know the extent to which those who take such experiential courses share learned skills with their colleagues, staff, and/or patients.

\section{Conclusion}

The modest resources that elective MBM courses require to enhance clinician resilience would likely be worth the investment, at least for those students who feel they are being overwhelmed by the inevitable challenges and stresses they are only beginning to encounter; stressors that will persist as they engage in their chosen professions.

\section{References}

1. Goldhagen BE, Kingsolver K, Stinnett SS, Rosdahl JA (2015) Stress and burnout in residents: impact of mindfulness-based resilience training. Adv Med Educ Pract 6: 525-532.

2. Lahoz MR, Mason HL (1990) Burnout Among Pharmacists. American Pharmacy 30(8): 28-32.

3. Dyrbye LN, Shanafelt TD, Werner L, Sood A, Satele D, et al. (2017) The Impact of a Required Longitudinal Stress Management and Resilience Training Course for First-Year Medical Students. Journal of General Internal Medicine 32(12): 1309-1314.

4. Dyrbye L, Thomas M, Shanafelt T (2006) Systematic Review of Depression, Anxiety, and Other Indicators of Psychological Distress Among U.S. And Canadian Medical Students. Acad Med 81(4): 354-373.

5. Guthrie E, Black D (2018) Psychiatric disorder, stress and burn out. Advances in Psychiatric Treatment 3(5): 275-281.

6. Aiken LH (2002) Hospital Nurse Staffing and Patient Mortality, Nurse Burnout, and Job Dissatisfaction. JAMA 288(16): 1987-1993.

7. Beall JW, De Hart RM, Riggs RM, Hensley J (2015) Perceived Stress, Stressors, and Coping Mechanisms among Doctor of Pharmacy Students. Pharmacy (Basel) 3(4): 344-354.

8. Dyrbye LN, Harper W, Durning S J, Moutier C, Thomas MR, et al. (2011) Patterns of distress in US medical students. Med Teac 33(10): 834-839.

9. Dyrbye LN, Thomas MR, Harper W, Massie FS, Power DV, et al. (2009) The learning environment and medical student burnout: a multicentre study. Med Educ 43(3): 274-282.

10. Kulig CE, Persky AM (2017) Transition and Student Well-being - Why We Need to Start the Conversation. Am J Pharm Educ 81(6): 100.

11. Leiter MP, Spence Laschinger HK (2006) Relationships of work and practice environment to professional burnout: testing a causal model. Nurs Res 55(2): 137-146.

12. Pathipati AS, Cassel CK (2018) Addressing Student Burnout: What Medical Schools Can Learn From Business Schools. Acad Med 93(11): 1607-1609.

13. Singh S, Prakash J, Das RC, Srivastava K (2016) A cross-sectional as- 
sessment of stress, coping, and burnout in the final-year medical undergraduate students. Ind Psychiatry J 25(2): 179-183.

14. Shanafelt TD, Balch CM, Bechamps G, Russell T, Dyrbye L, et al. (2010) Burnout and medical errors among American surgeons. Ann Surg 251(6): 995-1000.

15. West CP, Tan AD, Habermann TM, Sloan JA, Shanafelt TD (2009) Association of resident fatigue and distress with perceived medical errors. JAMA 302(12): 1294-1300.

16. Stucky ER, Dresselhaus TR, Dollarhide A, Shively M, Maynard G, et al (2009) Intern to Attending: Assessing Stress Among Physicians. Acad Med 84(2): 251-257.

17. Coffey CE, Elliot KE, Goldblatt E, Grus C, Kishore SP, et al. (2017) Burn out Among Health Care Professionals: A Call to Explore and Address This Underrecognized Threat to Safe, High-Quality Care - National Academy of Medicine. Retrieved.

18. Dyrbye LN, Shanafelt CA, Sinsky PF, Cipriano J, Bhatt A, et al. (2017) Burnout Among Health Care Professionals: A Call to Explore and Address This Underrecognized Threat to Safe, High-Quality Care - National Academy of Medicine. Retrieved.

19. Finkelstein C, Brownstein A, Scott C, Lan YL (2007) Anxiety and stress reduction in medical education: an intervention. Med Educ 41(3): 258264.

20. Kraemer KM, Luberto CM, O’Bryan EM, Mysinger E, Cotton S (2016) Mind-Body Skills Training to Improve Distress Tolerance in Medica Students: A Pilot Study. Teach Learn Med 28(2): 219-228.

21. Lee J, Graham AV (2001) Students' perception of medical school stress and their evaluation of a wellness elective. Med Educ 35(7): 652-659.
22. Saunders PA, Tractenberg RE, Chaterji R, Amri H, Harazduk N, et al. (2007) Promoting self-awareness and reflection through an experiential mind-body skills course for first year medical students. Medical Teacher 29(8): 778-784.

23. Shapiro SL, Shapiro DE, Schwartz GE (2000) Stress management in medical education: a review of the literature. Acad Med 75(7): 748759.

24. Rosenzweig S, Reibel DK, Greeson JM, Brainard GC, Hojat M (2003) Mindfulness-based stress reduction lowers psychological distress in medical students. Teach Learn Med 15(2): 88-92.

25. Shapiro SL, Schwartz GE, Bonner G (1998) Effects of mindfulness-based stress reduction on medical and premedical students. J Behav Med 21(6): 581-599.

26. Kennedy V (2010) Genograms. MAI Review (3): 1-12.

27. Osho Kundalini Meditation. Osho Kundalini Meditation. Retrieved February 16,2018

28. Bio Energy Meditation (Shaking Yoga) Bio Energy Meditation (Shaking Yoga). Retrieved February 16, 2018

29. How to Do Power Shaking Meditation | Wellness. Happiness. Mindfulness (2018). How to Do Power Shaking Meditation | Wellness. Happiness. Mindfulness.

30. Stetka B (2017) Where's the Proof that Mindfulness Really Works? Scientific American Mind 29(1): 20-23.

31. Reeves S, Zwarenstein M, Goldman J, Barr H, Freeth D, et al. (1996) Interprofessional education: effects on professional practice and health care outcomes 28(3): CD002213.

\section{Your next submission with Juniper Publishers will reach you the below assets}

- Quality Editorial service

- Swift Peer Review

- Reprints availability

- E-prints Service

- Manuscript Podcast for convenient understanding

- Global attainment for your research

- Manuscript accessibility in different formats

(Pdf, E-pub, Full Text, Audio)

- Unceasing customer service

Track the below URL for one-step submission

https://juniperpublishers.com/online-submission.php 